\title{
OS NOVOS BACHARÉIS EM DIREITO NO \\ BRASIL NO INÍCIO DO SÉCULO XXI - PRIMEIRAS CONSIDERAÇÕES
}

Fenando Facury Saff *

RESUMO: O artigo refere-se à politica publica da educaçăo como prestador de serviço ass bacharéis de direito em instituiçoes públicas e privadas no século XXI.

ABSTRACT: The article refers to the public polites of the education like servicable to law graduate in public and private institution in the twenty one century.

ZUSAMMENFASSUNG: Der Aufsatz behandelt de Ausbildungspolitik als Dienstleistung fur die juristische Grundausbildung in offentlichen und privaten Einrichtungen im 21. Jahrhundert.

PALAVRAS-CHAVE: Bacharéis em direito. Politica publica. Instituiçáo pública e privada como prestadora de servico.

KEY-WORDS: Law graduate. Public politics. Public and private intitutions like serviceable.

SCHLUSSELWÖTER: Juristische Grundausbildung. Ausbildungspolitik. Offentliche und private Einrichtungen als Dienstleister.

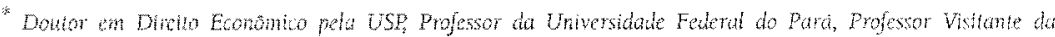

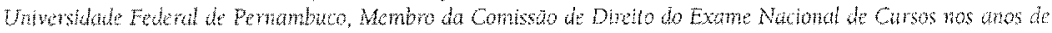
$109 \%, 98,59$ E 2000 .
} 
1. Primeiro passo antes de qualquer açäo visando intervit em uma dada realidade é saber qual é o público-alvo imediato. Qual a necessidade que possuem acerca do serviço que será ofertado, quais suas aspiraçoes, como vivem, qual seu poder aquisitivo, o que pensam etc.

Isto serve tanto para as açoes públicas como para as privadas. A dilerenca lica por conta dos objetivos perseguidos pelo sujeito ativo.

E regra geral que as atividades privadas busquem o lucro no desenvolvimento de suas atividades, o que faz com que sua análise tenha por norte um padräo de mercado lucrativo - um lucro tanto melhor quanto maior: Esta regra preside a analise que deve ser efetuada pelo segmento privado quanto aos usuários dos bens e serviços a serem oferecidos.

E também regra geral que as atividades vinculadas ao setor público devem ser exercidas sem o objetivo de lucro². Mas nem por isso se deve descurn da análise dos dados referentes a populacão usuária dos servicos a serem prestados. O objetivo neste caso será o de prestar um mais amploe melhor servico, de modo a atender a finalidade para a qual foi criado: o de prestar bons servicos a maior parte da populacáo.

Dấ que os paranmetros públicos devem ser diversos da análise privada do mesmo objeto: na análise privada, deve-se objetivar a obtencăo do maior horo possivel por unidade de produça; na análise pública a busca deve ser por melthor prestaça de serviços, visando alcançar objetivos estratégicos para toda a sociedade, independente da existência de lucro. Logo, em qualquer dos casos, a málise dos dados se impóe. O olhar sobre os dadose que deve ser distinto em razão do sujeito ativo da análise e do objetivo a ser alcancado.

Apenas a titulo de exemplo, pode-se cogitar sobre o que atenderia a maior parte da populaca brasileira: estudos sobre a enadicacão de doencas endenicas, como a malária ou a leshmaniose, ou estudos sobre cirurgias

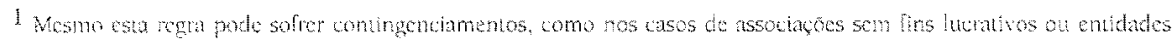
liminoplats.

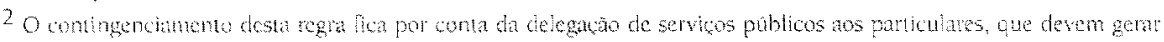

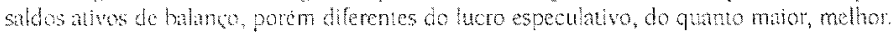


plásticas estéticas? Ambos os estudos são de extrema importância, mais o resultado será diverso de conformidade com o perfil do analista dos dados.

A pergunta acima se reveste de superior importância quando está em jogo o uso dos recursos públicos e a construção de um país que possui inegáveis disparidades sócio-econômicas, como o nosso. A intuitiva resposta poderia se dar através da indicação da preponderância do estudo das doenças endêmicas - o que deveria ser priorizado pelos dispêndios com verbas públicas -, porém jamais de forma a impedir que grupos privados atuem e desenvolvam estudos sobre outras atividades da medicina que tenham seu próprio público (leia-se: mercado lucrativo), observados preceitos técnicos e éticos estabelecidos pelo setor, com a participação incisiva do poder putilico.

No campo da educação superior, é imprescindível saber qual o papel que foi destinado pela sociedade na ordem jurídica aos entes públicos e privados que compöem o sistema educacional brasileiro. Daí porque a leitura do dados de setor é de suma importância para eventuais correçoes de rota.

Durante muitíssimo tempo a preocupação com o levantamento dos dados dos usuários da educação superior no Brasil não esteve presente no rol de preocupaçóes do Ministério da Educação. Apenas com a introdução de instrumentos de avaliação por parte desse Ministério, capitaneados pela iniciativa pioneira efetuada no ambito da Ordem dos Advogados do Brasil para as profissoes jurídicas, é que o setor de educação superior passou a ter dentre suas preocupaçoes a pergunta sobre quem são os primeiros destinatários do ensino superior brasileiro? E daí se poder ter um perfil sobre quem serăo os novos bacharéis em Direito no Brasil no início do século XXI.

2. Estas consideracoes assumem desdobrado relevo quando se verifica que o Direito passou a exercer uma função projetiva, na concretização das aspiracões futuras de uma sociedade, não mais existindo apenas para dar regulação às atividades sociais então existentes. É um formidável instrumento de implementaçăo de políticas, e não mais apenas um marco assecuratório de organização e condutas presentes e passadas. 
Logo, também no âmbito educacional, o Direito serve - junto com as demais áreas do conhecimento, em uma produçăo verdadeiramente interdisciplinar - como instrumento de indução e direção das atividades que se pretende ver implementadas na área da educação, nos diversos níveis em que hoje é dividida.

Daí que a Constituição de 1988 estabeleceu um conjunto de Princípios e Regras visando a ordenação do setor. Consta na Carta de 1988, por exemplo, que "a educação (é) direito de todos e dever do Estado e da família, (e) será promovida e incentivada com a colaboração da sociedade. visando ao pleno desenvolvimento da pessoa, seu preparo para o exercício da cidadania e sua qualificação para o trabalho", devendo haver "pluralismo de idéias e de concepções pedagógicas, e coexistência de instituiçóes públicas e privadas de ensino".

Foi assentado também pela Constituição de 1988 que o ensino é livre à iniciativa privada atendidas as condiçoes de cumprimento das normas gerais da educaçăo nacional $e$ a autorização e avaliação de qualidade pelo poder publico.

São múltiplos os papéis a serem desempenhados pelo poder público, dentre eles o de prestador de serviços na área do ensino, e o de instituidor de politicas educacionais. Fazendo um paralelo com uma classificação usual na dísciplina Direito Econômico, é como se o estado agisse na área educacional como participante do sistema, e sobre a área educacional, enquanto agente regulador do sistema". Obviamente, seu agir sobre a área educacional condiciona também sua atuação na área educacional . Portanto, é função precípua do poder público, em conjunto com os agentes privados, o estabelecimento de políticas públicas para o setor educacional. Daí porque a

\footnotetext{
3 An 205 , camtit.

4 Art 206 , incison.

5 Art. 200, pusm.

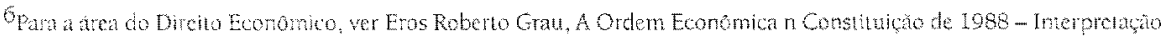
C Critak, SP, RT, 1000

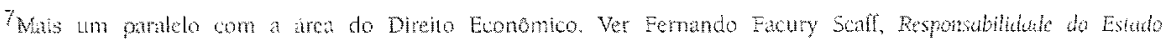
Intemencionikt, 5 s, surava, 1990
} 
acăo de regular - estabelecendo diretrizes em conjunto com a sociedade:obriga também o próprio poder público enquanto prestador de serviços.

Portanto, é com base nestes, e em diversos outros dispositivos da Constituição de 1988, que deve ser construído o sistema nacional de educaça no Brasil, e implementadas as politicas públicas para o setor ${ }^{9}$, que deve alcançar não apenas as instituições privadas, mas também as públicas, como acima relerido.

Desta forma, o estabelecimento de prioridades vinculadas ao levantamento dos usuários do setor torna-se mais relevante, a fim de que se possa delimitar quem são os utentes diretos daquele serviço e dirigir os esforços para a implementação dos objetivos fundamentais da existencia de uma República Federativa chamada Brasil: construcão de uma sociedade live justa e solidária, que garanta o desenvolvimento nacional, erradicando a pobreza e marginalização e reduzindo as desigualdades sociais e regionais e que promova o bem de todos, sem discriminações ${ }^{10}$. $O$ perfil do beneliciario dineto será descoberto no levantamento de dados efetuado. $O$ beneficiário indireto será toda a sociedade.

Assim, do intuito singelo, mercadológico, de lucro, passa-se a buscar um valor maior insculpido na Constituição de 1988, que são os objetivos fundamentais da existência desta República.

Portanto, o estabelecimento de politicas públicas para este setor, conCorme determina a Constituição, não implica em permitir - ou autorizar -, que o intuito lucrativo seja indiscriminadamente estabelecido. Ele deve existir a partir do momento que a Constituição permitiu sua existência; mas nāo deve presidir as análises do setor, que deve ser pautado por uma visāo estratégica de desenvolvimento nacional, de conformidade com o que estabelecem as normas acima mencionadas da Carta de 1988. Ou seja, a visāo pública como estratégico agente regulador deve ser dominante sobre a visão privatistica da atividade educacional.

\footnotetext{
8 Curpit do an, 205, CF.

9 plano matonal de educacan, de carater pluranual (art. 214, CF), é apenas um destes instrumenos.

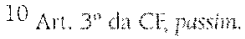


Será que isso está acontecendo em nosso país?

3. A discussão sobre os primeiros destinatários do ensino juridico toma contonos de destaque na área juridica, em razão do fato de que os bacharéis em Direito compöem um dos Poderes do Estado. Magistrados, membros do Ministério Público, Delegados de polícia, Procuradores e Advogados públicos e privados são egressos desse curso, o que lhe concede redobrada impontância e especial relevăncia, pois a qualidade do ensino nesta ârea relletirá diretamente no grau de desenvolvimento do Estado, e em sua capacidade de dar respostas às questöes sociais presentes e emergentes.

O destaque se acerba quando se trata da carreira docente, uma vez que serão estes que conduzirão as futuras geraçōes ao saber necessário para o alcance das metas cque a sociedade se propôs nesta área.

Portanto, é fundamental que se saba quem são tais alunos, pois eles serão os bacharéis em Direito que operarão na sociedade tomando as decisoes juridicas (e, dentre elas, as judiciais) que conduzirăo este país nos próximos anos, para as próximas geraçōes.

Desta forma, este trabalho visa dar uma inicial contribuiça para o delineamento deste perfil, demonstrando quem săo os bacharêis em Direito que as Instituiçóes de Ensino Superior estão gerando neste país.

4. Em primeiro lugar deve-se acentuar que se trata de uma primeira aproximaça do tema, que pode e deve ser mais amplamente explorado pelos operadores educacionais, mais especialmente os que se encontram envolvidos com a área jurídica. Muitas outras perguntas devem ser formuladas visando trazer luz a pontos obscuros e outras respostas poderão ser prestadas a partir das análises primeiras que estão sendo feitas.

Os números que serăo apresentados referem-se aos dados fornecidos pelo INEP - Instituto Nacional de Pesquisas Educacionais, vinculado ao Ministério da Educacão, obudos junto aos concluintes do curso de bacharelado em Direto em todo o país, cadastrados para realização do ENC 
- Exame Nacional de Cursos" de 1998. Os dados relerentes aos anos anteriores (1996 e 1997) também foram analisados, e quando indicarem disparidade acentuada seräo referidos. O instrumento avaliatório é conhecido no jargão por questionario-pesquisa.

Apenas os concluintes são alcançados por esta pesquisa do INEP, que toma por base o ENC, năo demonstrando o impacto da revolução estabelecida pela Portaria MEC 1886/94, cuja obrigatoriedade iniciou para os novos alunos matriculados a partir de 1997. Desta foma, o impacto positivo dos eleitos da Portaria $1886 / 94$ somente serão sentidos a partir do ano 2.001, quando as primeiras turmas formadas sob sua égide concluírem 0 curso.

Os dados coletados pelo INEP são riquíssimos para análise das peculiaridades regionais, uma vez que são demonstrados tambérn por Estado ou Região geográfica. Para os efeitos destas primeiras consideraçóes, não se irá abarcar este tipo de detathamento em todas as consideraçoes possiveis.

Vale ressaltar que incluso na categoria instituiçoes privadas encontramse tambem as confessionais, as comunitárias e as filantrópicas ${ }^{12}$. E na categoria instituicóes públicas estào insertas as federais, estaduais e municiparis ${ }^{3}$.

5. O universo estudado na pesquisa do ENC-98 é de 41.158 alunos, em 212 Instituiçóes de Ensino Superior - IES, sendo relevante notar que o ensino juridico no Brasil já se encontra em avançado estado de privatização.

146 instituiçôes de ensino superior concentram 33.050 alunos, o que corresponde a $80 \%$ (oitenta por cento) dos bacharéis em Direito do Brasil no ano de 1998. O que corresponde a uma média inear, abstrata, de 226 bacharéis em Direito por IES Privada no ano de 1998.

Apenas 66 IES são públicas, e correspondem a tão somente 8.108 discentes, o que alcança $20 \%$ (vinte por cento) dos bacharéis em Direito

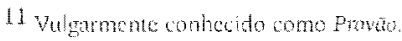

12 Lei 9394960 , ant. 20 ?

13 lct 9394796, ant. 19,1
} 
graduados no Brasil em 1998. O que alcança a média linear e abstrata de 122 bacharéis em Direito por IES Pública no ano de 1998.

Contudo, esta ampla privatização do ensino superior, que alcança mais de $80 \%$ dos bacharéis lançados no mercado em 1998 ${ }^{14}$, näo vem traduzindo diretamente a uma melhoria na qualidade do ensino jurídico. A distribuição dos resultados do Exame Nacional de Cursos de 1998 nos demonstra a seguinte situação:

$\begin{array}{ccccccc}\text { Conceitos } & \text { A } & \text { B } & \text { C } & \text { D } & \text { E } & {\mathrm{S} / \mathrm{C}^{13}}^{-15} \\ \text { IES Públicas: } & 15 & 13 & 20 & 08 & 09 & 01 \\ \text { IES Privadas: } & 10 & 25 & 64 & 30 & 16 & 01\end{array}$

Demonstremos sob outra forma estes conceitos concedidos às 210 LES avaliadas pelo ENC-98.

\begin{tabular}{llll} 
& IES Públicas & IES Privadas & Total \\
\hline A & $7,14 \%$ & $4,78 \%$ & $11,92 \%$ \\
B & $6,19 \%$ & $11,91 \%$ & $18,10 \%$ \\
C & $9,52 \%$ & $30,47 \%$ & $39,99 \%$ \\
D & $3,80 \%$ & $14,29 \%$ & $18,09 \%$ \\
E & $4,28 \%$ & $7,62 \%$ & $11,90 \%$ \\
\cline { 3 - 4 } & & Total & $100,00 \%$
\end{tabular}

As IES Públicas conseguiram a maior parte dos conceitos "A" (cerca de $60 \%$ ) e a menor parte dos conceitos " $\mathrm{E}$ " (cerca de $36 \%$ ). No grande conceito médio " $C$ " estão $30 \%$ das IES Públicas, e $44 \%$ das IES Privadas.

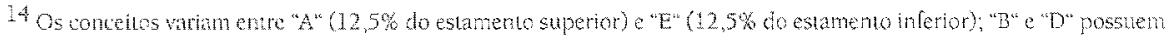
gualmenle $12,5 \%$ dos estamentos imediatamente proximos: e "C" para a grande média de $50 \%$, distribudos de confomidate com a ténica di Cura de Gatiss.

$15 \mathrm{~S} / \mathrm{C}=\mathrm{sem}$ concelo. Neste caso em decorrência de uma liminar concedida pela Justica Federal de Minas Gerats impedindo a aplicatäo do ENC-98 em Belo Horizonte, o que afastou a avalią̧o dos cursos de Direito de UFMG e da PUC.MG.

16 As ste now form consideradas. Ver nota anterior,
} 
Ou seja, até o ano de 1998 o ENC demonstra uma situação de superior qualificação do corpo discente nas IES Públicas" ${ }^{1 ?}$. Não se sabe até quando esta melhor qualificação será mantida.

6. Alguns pontos distintos sobre os números acima e suas disparidades devem ser considerados: os que se referem à privatização do ensino superior, e os que se referem à superior qualificação dos discentes das IES Públicas.

A disparidade na privatização tende a se acentuar, uma vez que vários novos cursos de graduação em Direito foram autorizados pelo Conselho Nacional de Educação nos dois ültimos anos, todos em IES Privadas, e que somente seräo atingidos pela pesquisa do ENC quando os discentes alcançarem o último ano do curso. E mais, as Universidades prescindem de autorizaçăo do Conselho Nacional de Educação para criar novos cursos ${ }^{13}$, o que induz a crer que o número de bacharéis em Direito irá aumentar sensivelmente nos próximos anos. A disparidade acima referida será intensificada pelo fato de que as verbas para a educaçăo superior pública estão minguando, e a contratação de novos professores não está sendo autorizada. Logo, apenas as universidades privadas estão lançando mão de sua autonomia para criação de novos cursos juridicos e para o aumento do número de vagas. Daí que o número de vagas das IES Privadas tende a crescer, e o das IES Públicas a se estabilizar. Portanto, a disparidade da privatizaça do ensino jurídico tende a se acentuar.

De outra banda, a disparidade no que se refere à qualidade dos discentes das IES Públicas não é algo que seja assegurado, em razäo de alguns dos problemas acima referidos, quais sejam: reduçäo das verbas das

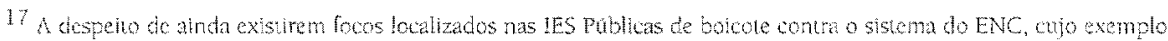
mais signilcutivo es a entreg das provas em branco - o que e considerado como resposla incoreta pelos indices

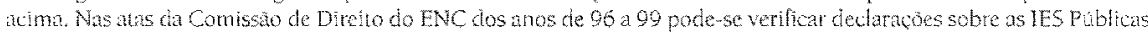

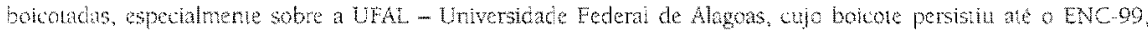
segundo informaçoes do Diretor do Centro de Ciênutas Juridlas e membro da Comissăo, Prof. Paulo luiz Netio Lobo. A esalistica alcanca apenas as provas $100 \%$ en bratco enāo aquelas em que apenas una questäo e assinalada. Em 1999 o perentual das provas $100 \% \mathrm{em}$ branco e insignificante, $0,4 \%$ do totat para a area de Direlto.

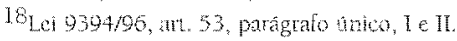


IES Públicas, diminuição da remuneração do funcionalismo público como um todo - docentes inclusos -, e velado incentivo à aposentadoria com proibição de contratação de novos docentes. Tudo isto faz com que haja verdadeira migração de cérebros das IES Públicas para as Privadas, sem a devida possibilidade de reposição da mesma qualidade acadêmica naquelas. E, em alguns casos, sequer da mesma quantidade acadêmica' ${ }^{19}$.

Ademais, na área do ensino jurídico, é preocupante a exigência constante da nova Lei de Diretrizes e Bases da Educação que requer, a partir do ano de 2005, que um terço do corpo docente das Universidades seja composto de mestres ou doutores. Levando-se em conta que, segundo a CAPES, o prazo de formação de um Mestre deve ser entre 30 e 36 meses (cerca de 03 anos), e que existem poucos cursos de Mestrado em Direito no Brasil, e muito menor número de Doutorado, teme-se pela queda da qualidade da produção acadêmica nos cursos de pós-graduação. Contudo, esta é uma preocupação que alcança indistintamente IES Públicas e privadas, preocupando o destinatário indireto desta política, que é a sociedade.

7. Verifica-se, portanto, que as instituições mantenedoras das IES Privadas estão investindo no ensino jurídico por entenderem ser um bom negócio, por razóes econômicas de mercado, de mercado lucrativo. As instituições mantenedoras clas IES Públicas estão deixando de lado os investimentos nesse setor por entenderem que se trata apenas de um negócio econômico de mercado, não vislumbrando a importância que o setor possui para 0 desenvolvimento do Estado, o que ultrapassa a singela análise mercadológica lucrativa.

O Poder Público, em sua função regulamentar, de coordenar políticas públicas para o setor educacional, esquece que o ensino não é uma singela questão de mercado econômico, de intuito lucrativo, mas uma função estratégica para o futuro de um país. Não há como sobrexistir um país sem

\footnotetext{
19 Aliás, deve-se relerir que nas yES Públicas federais qualquer reposiço de pessoal está vedada hí tempos, licando tais IËS nas măos de prolessores substitulos ou de mestrandos em programa de treinamento, o que e academicamente clesaconseltado da foma que vem sendo efetuado, pois centra o ensino em quem ainda nio completou seu cicto de aptendizado.
} 
uma estratégia educacional arrojada, que dirija as açoes públicas e privadas para o desenvolvimento nacional e o ultrapassamento dos problemas internos emergentes e urgentes, principalmente no que tange à erradicação das desigualdades sociais e econômicas e ao direcionamento do desenvolvimento nacional, ultrapassando o singelo intuito lucrativo próprio de uma visão privatística da realidade.

E isto ocorre justamente quando o mundo discute o pós-Consenso de Washington, revendo dogmas neo-liberais. Joseph Stiglitz, vice presidente do Banco Mundial, fez publicar nos principais jornais do planeta artigo intitulado "Conhecimento é que Gera Prosperidade", onde, entre outros aspectos, comenta o lato de que a Costa Rica, país com renda per capita infinitamente menor que os países desenvolvidos, possui expectativa de vida e nivel de mortalidade infantil no mesmo patamar de muitos paises de $1^{\circ}$ mundo. Diz Stigliz que tal fato decorre de décadas desenvolvendo politicas públicas de disseminação do conhecimento em várias áreas, inclusive na prevenção de doenças.

Outra instituição internacional que traz dados interessantes para o debate é BID - Banco Interamericano para o Desenvolvimento. Em recente estudo denominado "A América Latina lace às Desigualdades" vincula as disparidades da concentração de renda com o número de anos de estudo. Daí que, no Brasil, a situaçào é a seguinte:

Os $10 \%$ mais ricos possuem $47 \%$ da riqueza nacional, e tiveram, em média, 11 anos de escolaridade;

- Os $10 \%$ mais pobres possuem abaixo de $1 \%$ da riqueza nacional, e tiveram, em média, apenas 02 anos de escolaridade.

- Destes $10 \%$ mais pobres, apenas $19 \%$ completaram o curso primário.

É uma disparidade inigualável na América Latina. Apenas o Paraguai e El Salvador chegam próximo a tal grau de iniquidade.

$\mathrm{E}$, tomandomse por base os dados de toda a América Latina, constatase que no percentual dos $10 \%$ mais ricos, apenas $14 \%$ săo empresários,

20 Excros deste estudo form publicados no jomal Folla de Sao Paulo, 14/1 198, caderno Brabil, mag. Lo 
sendo os demais profissionais liberais ou assalariados, o que comprova o predominio do saber para a melhoria das condições materiais de vida, e não apenas dos meios tradicionais de produção, como anteriormente se acreditava.

O resultado das políticas públicas adotadas no Brasil é que a despeito de sermos a $8^{a}$ economia mundial, os indicadores de qualidade de vida nos colocam em $79^{\circ}$ lugar, arrás de países como Malásia, Suriname, Equador e Macedonia ${ }^{2 !}$.

8. Ouro aspecto interessantíssimo da pesquisa do INEP com dados do ENC-98 diz respeito a formação que os bacharéis em Direito receberam no ensino médio.

$48,4 \%$ cursaram ensino médio integralmente em escolas privadas, contra $30,2 \%$ que o fizeram integralmente em escolas públicas ${ }^{22}$.

Contudo, quem ingressou em IES Pública majoritariamente cursou todo o ensino médio em escola privada e não em escola pública (lederais $56 \% \times 27 \%$; estaduais $59,0 \% \times 25,0 \%$; e municipais $44,0 \% \times 33,0 \%)$. E quem ingressou em IES Privadas, em sua maioria, também cursou todo o ensino médio em escola privada e näo pública $(47 \% \times 31,0 \%)$.

Este item nos permite fazer uma afirmativa que desmente colocaçoes até então tidas como verdadeiras ${ }^{23}$ : a de que os alunos das IES Públicas provinham do ensino médio privado, e que os alunos das IES Privadas provinham do ensino médio público. Os dados não confirmam esta assertiva.

Os dados nos colocam uma situação muito mais excludente do que a suposta: so Ingressa no ensino supertor do Diretto, em IES PÚblicas oU PRIVADAS, QUEM PROVEIO DO ENSINO MEDIO PRIVADO ${ }^{24}$.

21 Relatorio de 1999 do PNUD - Programa das Naçoes Unidas para o Desenvolvimento, apurado segundo o indice de Desenvolvimento Humano - DH. Jornal Folha de 5ão Paulo, 11/07/99, caderno Brasil/qualidade de vida. A Madisia

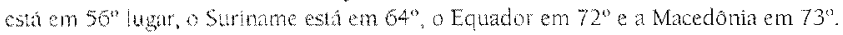

22 Outras peruntis tweram respostas menos votadas: ensino mais público que privado $(7,9 \%)$, mais privado que publon $(7,7 \%)$, e metade público, melade privado $(4,5 \%)$

23 o que tambem foi observado pela equipe do INEP. Ver comentátio a tabela 7 das respostas a questionáriorpesquisa de 1998

24 A cquipe do TNEP no mencionou csu conciusto em sua analise, apenas infimou a voz corrente de que os alunos das IES Tublicts provinam do ensino medio privado, e que os alunos das IES Frivadas provinham do ensino médio público. 
Por outras palavras, quem estudou no ensino médio público tem suas chances de ingresso em uma IES reduzidas em, no mínimo 1/3, uma vez que este $e$ o percentual dos graduandos em Direito que proveio do ensino médio público. Esta é a regra da exclusão social demonstrada pelos números, e que reforça a tese da iniquidade da distribuição do saber nos diversos niveis de ensino em nosso pais.

Aliás, está nāo é uma afirmativa cabivel apenas para os bacharéis em Direito. Dos 10 cursos submetidos ao ENC-9825, apenas 02 mostraram dados diversos neste item: Letras (onde $59,0 \%$ cursou integralmente ensino médio público contra $20,5 \%$ privado) e Matemática (onde $64,7 \%$ cursou ensino médio público contra $18,7 \%$ privado). Os dados fornecidos com referência a estes dois cursos näo nos permitem cruzar estas informaçöes com o destino desses alunos, se para IES Públicas ou privadas.

9. A renda familiar mensal dos graduandos também é outro fator muito interessante para ser analisado.

a) $31,4 \%$ tem renda familiar mensal situada entre $\mathrm{R} \$ 2.600,00 \mathrm{a} \mathrm{R} \$$ $6.500,00$ (entre 20 e 50 salários mínimos).

b) $28,7 \%$ está situada na faixa entre $R \$ 1.300,00$ a $R \$ 2.600,00$ (10 e 20 salários minimos) de renda familiar mensal.

c) $22,7 \%$ está situada a laixa entre $R \$ 391,00$ a $R \$ 1,300,00(03$ a 10 salários mínimos) de renda familiar mensal.

d) $12,8 \%$ tem renda familiar mensal acima de RS 6.500,00 60 salarios minimos).

e) 2,9\% tem renda familiar mensal abaixo de $\mathrm{R} \$ 390,00$ (03 salários mínimos).

Vale ressaltar que grande parte dos discentes também trabalhou durante o curso. $37,5 \%$ dos bacharelandos trabalhou em tempo integral durante o curso; 22,2\% trabalhou entre 20 e 40 horas semanais enquanto cursava a graduação em. Direito; $12,3 \%$ realizava trabalhos eventuais, sem

\footnotetext{
25 Administräo, Direito, Engenharia Cwil, Engenhara Eletrea, Engenhatia Qumica, Jornalismo, Leiras, Matematica, Medicina Veteriníria, Odontologie.
} 
vinculo empregatício e 11,6\% trabalhou até 20 horas semanais. Apenas $14,9 \%$ não trabalhou enquanto cursava a graduação em Direito. Presume-se que a remuneração deste trabalho esteja inserido nos números referentes à renda familiar acima transcritos.

Coloquemos estes valores em correlação com os grandes números nacionais. A renda per capita brasileira em 1998 correspondeu a US\$ 4.500,00 (quatro mil e quinhentos dólares norte americanos) anuais, o que alcança um valor médio de US $\$ 375,00$ (trezentos e setenta e cinco dólares notte americanos) mensais, equivalentes naquele ano a R\$ 450,00 (quatrocentos e cinqüenta reais) mensais ${ }^{26}$.

Com tais números pode-se afirmar que a maior parte dos graduandos em Direito possui relaça sócio-econômica privilegiada em face da maioria da populaçăo brasileira. Levando-se em conta que a familia do graduando em Direito é constituída, majoritariamente, por pai, mäe e dois irmãos, verifica-se nos números ideais um montante de $\mathrm{R} \$ 2.250,00$ ( $\mathrm{R} \$ 450,00 \mathrm{x}$ 5 pessoas). Com os dados acima disponiveis, pode-se afirmar que pouco mais de $60 \%$ dos graduandos em Direito encontram-se na média ou acima do patamar médio da renda per capita nacional.

Pode parecer ao analista mais desavisado que o fator "tenda" acima descrito seja responsável pelo fato de que $75,8 \%$ dos bacharéis em Direito não utilizaram nenhum tipo de bolsa de estudos durante o curso. $9,5 \%$ teve bolsa parcial da IES (o que só pode ocorrer nas IES Privadas) e 7,9\% lançou mão de crédito educativo. Porém esta assertiva não será real, uma vez que dos demais 09 cursos analisados, a esmagadora maioria näo teve nenhum tipo de bolsa de estudos. O percentual mais baixo é do curso de Matemática, onde "apenas" 69,20\% menciona nunca ter recebido bolsa de estudos para cursar graduaça.

Parece-nos que se trata de um viés da política pública educacional não conceder bolsas de estudos para os discentes na graduação, mesmo em um pais onde este nivel de ensino encontra-se majoritariamente privatizado (pelo menos na área do ensino jurídico).

26 Cumbio medio de US5 $1,00=$ as 1,20 no ano de 1998 . 
10. A pesquisa do INEP acerca do ENC-98 demonstra-nos também que a maioria dos discentes que concluem o bacharelado em direito estuda a noite $(60,3 \%)$, é composta predominantemente de pessoas solteiras $(6 ., 14 \%)$ e sem filhos $(72,6 \%)$. A maioria é composta de mulheres $(50,9 \%)$, sendo que a maior parte dos discentes tem menos de 24 anos ${ }^{27}$.

Como acima referido, o discente é oriundo de família composta por mais dois irmãos $(30,1 \%)$, sendo que morou com os pais durante o curso $(63,4 \%)$.

Seu pai possui grau de escolaridade superior $(36,2 \%)$, sendo o segundo grupamento o que estabelece $1^{\circ}$ grau incompleto $(27,6 \%)$. Os dacos não nos permitem aprofundar esta análise.

A disuibuiça é mais equânime no que se refere ao grau de escolaridade da mae dos graduandos em direito: $27,4 \%$ tem o $1^{\circ}$ grau incompleto; $27,3 \%$ tem nivel superior; e $26,1 \%$ possui o $2^{\circ}$ grau completo. Esta distribuição mais linear é outra questão que os dados não nos permitem confrontar para maiores explicações.

11. O levantamento de dados demonstrou também que os bacharelandos em Direito no Brasil consomem poucas horas de estudo semanais fora de sala de aula. 36,3\% estudam apenas de 01 a 02 horas por semana lora de sala de aula; 32,1\% alegam estudar de 03 a $05 ; 11,9 \%$ de 06 a 08 horas fora de sala de aula semanais; e apenas $9,8 \%$ mencionam estudar mais de 08 horas semanais. O expressivo numero de $8,7 \%$ deciara que so assiste as aulas, sem nenhuma hora a mais de estudo extraclasse.

A intimidade dos discentes com a informática também nảo é um dado lorte. $46,2 \%$ declaram que só usam o micro como processador de Lextos, desconhecendo o uso de outros programas. E 31,7\% nunca tiveram a oportunidade de acessar a Internet. Pode parecer um dado isolado da área juridica, mas não é. Analisando as outras áreas pesquisadas, verificamse que esta resposta também foi majoritaria em Administraç̄̃o. Letras, Matemática e Odontologia.

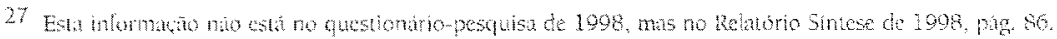


Os discentes também possuem pouco hábito de leitura, uma vez que, consultados sobre a média de livros näo-escolares lidos durante o curso, a maioria de $38,1 \%$ respondeu que lia entre 02 a 03 por ano. Em um distante segundo lugar estão aqueles que lêem 06 ou mais livros por ano $(17,2 \%)$, praticamente empatados com os que leem apenas 01 livro não escolar por ano $(17,0 \%)$.

Outro aspecto pouco valorizado nos cursos juridicos, o que reflete na concepcão de bacharel em direito que está sendo formado em nossas escolas, diz respeito ao conhecimento de línguas estrangeiras. Solicitados a autoavaliar seu conhecimento em línguas estrangeiras, o resultado foi, para o idioma Inglès: $38.9 \%$ auto avaliaram seu conhecimento como nulo, e $22,2 \%$ admitiram que apenas leem nessa língua. Para o idioma Espanhol: 51,7\% admitiram conhecimento nulo nessa língua, e $34,6 \%$ que nela apenas lêem. Foram também consultados a declinar em qual lingua estrangeira é melhor sua capacidade de comunicaçăo, havendo sido indicados os seguintes idiomas: Francês, Alemäo, Italiano e Japonês. A resposta maciça foi "nenhuma dessas", com $65,2 \%$.

$\hat{E}$ de pasmar, mas nas demais áreas consultadas, a resposta majoritária a este último item foi identica, variando entre $61,6 \%$ (Jornalismo) a $78,8 \%$ (Matemática). As respostas das demais áreas ao conhecimento de lingua inglesa e espanhola foi, em média, parecido com o do Direito.

12. Diversas outras consideraçóes podem ser efetuadas com o vasto material coletado através do questionário-pesquisa que é fornecido com antecedència aos bacharelandos que são examinados pelo Exame Nacional de Cursos, tais como análise das Instituiçoes, de sua Biblioteca, do corpo docente etc. O presente estudo é apenas uma primeira tentativa de aproximação do objeto, que deve ser melhor trabalhado.

Contudo, mesmo estas primeiras consideraçōes devem-nos fazer refletir sobre o papel dos docentes, dos discentes, das Instituiçôes de Ensino Superior (Públicas e Privadas) e do Poder Publico, responsaveis pelo estabelecimento e pela condução das políticas públicas para a educação.

De nada adiantará o estabelecimento de perfis e habilidades como as que a Comissão de Direito junto ao Exame Nacional de Cursos vêm traçando 
nestes anos de 1996 a $1999^{28}$, se tal conhecimento não chegar à sala de aula com eletividade, sem retóricas ou dissimulações. É necessário que os discentes tomem consciência de seu papel em uma sociedade periférica e desigual, que investe em sua qualificação em detrimento de outras prioridades sociais.

De nada adiantará todo o esforço do corpo docente na área jurídica usualmente voluntarista, em razâo do chamado de mercado das demais prolissões jurídicas -, se as IES não fizerem sua parte, dando aos prolessores e alunos melhores condições para o desenvolvimento da relação ensino aprendizagem.

De nada adiantará exigências de conhecimento de Internet, de línguas, de interdisciplinariedade, se os professores a isso não conscientizarem os alunos. E eles próprios näo vierem a ser despertados para esta nova necessidade de transmissão do saber, e treinados para isso.

E de nada adiantará todo este esforço se os poderes públicos continuarem a se ausentar de seu papel condutor de políticas públicas para o setor educacional brasileiro, ora deixado ao bel prazer de laisse faire, laisse passe, do século XIX, o que imprime uma visão essencialmente privatística para a condução do setor, não possibilitando a construção de uma sociedade mais justa, plural e democrática, que busque o desenvolvimento nacional com a redução das desigualdades, e comprometida com a ética e a mais ampla disponibilização de meios para o acesso de todos à educação A visão deve ser pública, como pública deve ser a política para o setor, construída em conjunto com a sociedade.

28 Dircrizes efeluadas pela Comissão de Direito do ENC-99. Habilidades: leitura e comprecnsāo de textos e documentos; interpretakno e aplicaçao do Direito; pesquisa e utilizacão da legislaçió, da jurispruclência, da dourina e de outras fontes do Direito; produção crialiva do Direito; correta utilização da linguagem - con clareza, precisâo e propriedade - fluência ve bal e riqueza de vocabulário; uilização do raciocinio lógico, de argumentação, de persuasão c de reflexĩo critica; julgamento e tomada de decisóes; utilizaçāo de instrumentos e técnicas pan conhecimeno e

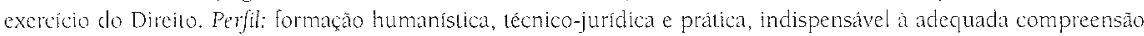
interdisciplinar do fenomeno jurídico c das transformaçóes sociais; senso ético profissional, associado á responsabilidade sortial, com a compreensão da causalidade e finalidade das normas juridicas e ta busca constante da libertação do homen e do aprimoramento da sociedade; capacidade de apreensão, transmissão crítica e produçãn criativa do Direito, ala da ao raciocínio lógico e à consciência da necessidade de permanente atualizą̧ao; capacidade para cquacionar problemas e buscar soluçōes harmönicas com as exigências sociais; capacidade de desenvolver formas exurajudiciais de prevençăo e solução de conflitos individuais e coletivos; visão atualizada de mundo e, em particular, consciencia dos problemas de seu tempo e de seu espaço. 
13. Neste sentido, deve-se retornar à primeira parte deste trabalho, onde se demonstra a necessidade de consultar o público-alvo para o estabelecimento de políticas públicas para o setor.

Fruto de um processo longo, porem democrático, de consulta à vários atores sociais deste processo, em vários rincoes do pais, resultou a proposta de elaboraça de uma Portaria que modificasse os padroes para o ensino juridico no Brasil. E daí resultou a Portaria 1886/94, que estabeleceu novas diretrizes cumculares e patamares minimos para a criação e a manutenção de cursos jurídicos no país. Como acima referido, sua aplicação foi iniciada a partir dos a novos alunos matriculados em $1997^{24}$, o que implica em dizer que seus efeitos somente poderão ser alcançados pelo sistema do ENC a partir do ano 2.001 .

Pois bem. Pretende-se pura e simplesmente revogar esta Portaria antes que seus eleitos possam ser sequer dimensionados, a fim de corrigin eventuais desvios de percurso $0^{\circ}$. É imperiosa a manutenção das diretrizes da Portaria 1886/94. Somente após o ENC do ano 2.001 é que se poderá eletivamente apurar se houve a melhoria do ensino juridico brasileiro, hoje apenas intuida nos diversos encontros nacionais e regionais realizados nos ultimos anos sobre o ensino jurídico no Brasil.

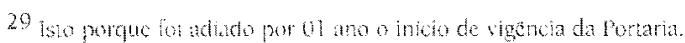

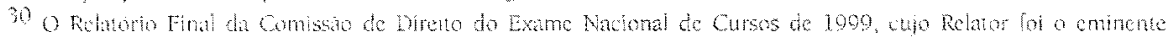

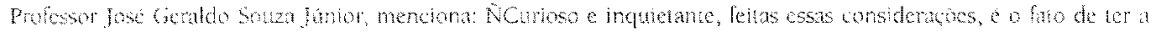

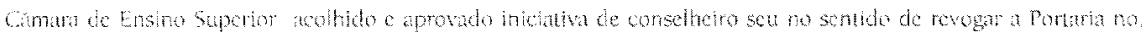

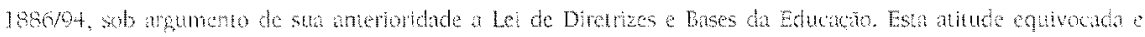

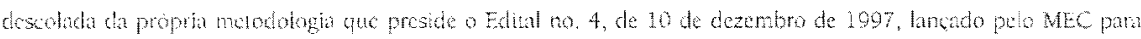

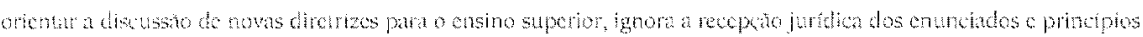

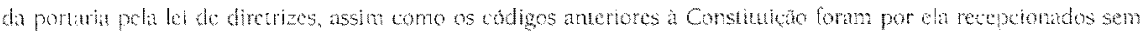

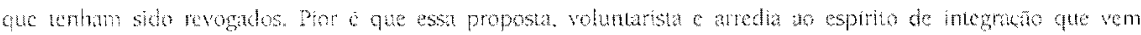

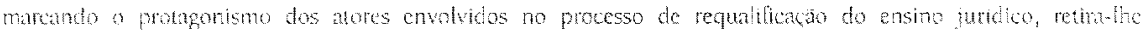

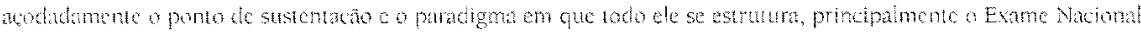

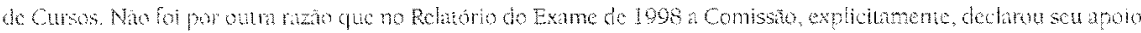

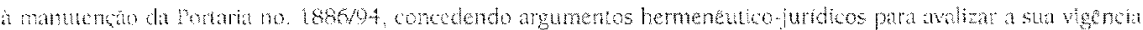

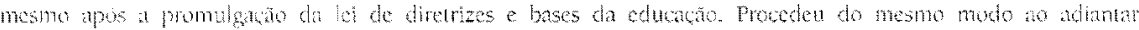

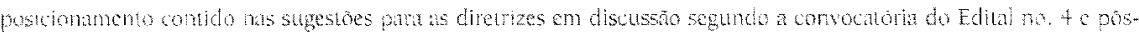

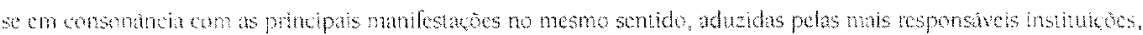

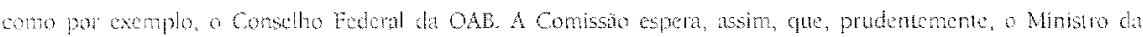

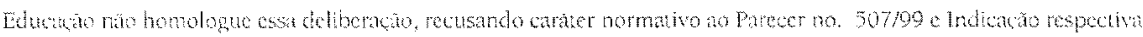
(100. 1/\%)." 
Como é que se pode revogar um politica pública, gestada em comum com a sociedade, quando seus efeitos năo foram testados pelo público-alvo pretendido? Como dimensionar seus efeitos, caso revogada? Precisamos de maior análise para poder deliberar sobre o tema.

Revogar a Portaria 1886/94 será privilegiar a visão privatistica, centrada no lucro, sobre a necessária visăo pública, estratégica para a realização de uma sociedade mais justa e solidária, baseada na melhor qualificação técnica e prática do bacharel em Direito. A revogação da Portaria $1886 / 94$ não atenderá aos reclamos da comunidade juridica e apenas demonstrará ainda mais a nudez do rei.

14. Enfim, se cada qual de nós não fizer algo para melhorar o atual estado de coisas, tudo ficará como está. Talvez ainda pior. Ou como "em Oran, e no resto do mundo, onde por falta de tempo e de reflexão, somos obrigados a amar sem saber" "Aprender, ensinar, amar e viver sem saber, são açöes que não devemos permitir que aconteçam, principalmente por falta de reflexão.

Devemos ultrapassar os umbrais do alerta dantesco "deixai toda esperança, ó vós que entrais" ${ }^{32}$, e realçar a importancia do estabelecimento de politicas públicas educacionais e, em especial, para o ensino juricico, vinculadas a visäo pública, estrategicamente social, deste bem imaterial que é de todos nós, e para todos nós, em nosso próprio proveito.

\section{BIBLIOGRAFIA}

ALIGHTri, Dame A DPVNA COMÉDIA, O Infemo, Canto III, verso 9. SP, Ed, 34, cd, bilingue, trad. Italo Eugenio Mauro, 1998.

CAMUS Abert A PESTE capitnlo I, SE, Ed. Abril Cultural, 1934.

FOLHA DE 5 ÃO DAULO. São Paulo, Ed. Folha da Manhă, ediça do dia 14/1198, Caderno Brasil, pág, 10.

\footnotetext{
3! A Peste, Abor Cawus, capitulo $\mathrm{r}$.

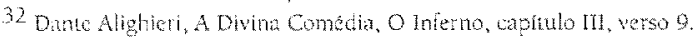


edicho do dia $11 / 07 / 99$, Cademo Brasilqualidade de vida que veiculou o Relatorio de 1999 do PNUD - Progrma das Naçoes Unidas para o Desenvolvimento, apurado segundo o indice de Desemolvimento Humano-IDH.

GRAU, EIOS Robcro. A ORDEM ECONOMICA N CONSTITULCAO DE 1988 - INTERPRETACAOE CRITICA. SP, RT, 1990.

INEP - Instiuto Nacional de Pesquisas Educacionais/ Ministerto da Educaço do Brasil. RELATÓRIO SINTESE de 1998. Brasila, 1998.

Relatorio Final da Comissa de Direito do Exame Nacional de Cursos de 1999. Brasilia, 1999.

QUESTIONARIO PESQUTSA. Brasilia, 1996

_- QUESTIONARIO PESQUSA. Bramila, 1997.

- QUESTIONARIO PESQUTSA. BMSHA, 1998.

SCATF, Fenando FaCUYY RESPONSABLIDADE DO ESTADO INTERVENCIONISTA. SE, SATATa, 1900. 